\title{
Optimization of Conditions for Charantin Extraction in PEG/Salt Aqueous Two-Phase Systems Using Response Surface Methodology
}

\author{
Chunchao Han* and Jihui Wang \\ School of Pharmacy, Shandong University of Traditional Chinese Medicine, Jinan, P.R China
}

\begin{abstract}
Momordica charantia, commonly known as karela or bitter melon, is used as a vegetable in Chinese, Indian subcontinent. However, in Chinese traditional medicine, the plant is usually used as an antidiabetic agent. One of the active components is charantin. Aqueous two-phase systems (ATPS) were used for the purifying saponin because of their low cost. ATPS can reduce amount of organic solvent and the danger of explosion necessitates special equipment leading to increased costs. The levels of blood glucose decreased after administration of charantin purified from Momordica charantia with (ATPS $(p<0.05)$.
\end{abstract}

Key Words: Momordica charantia, charantin, ATPS, RSM, extraction.

\section{INTRODUCTION}

Momordica charantia (family, Cucurbitaceae), commonly known as karela or bitter melon (Japanese name "Tsurureishi"), is used as a vegetable in Chinese, Indian subcontinent, South America. The fruit of this plant has been used as a bitter stomachic, a laxative, an antidiabetic, and an anthelmintic for children.

In the orient, Momordica charantia is not only a popular vegetable crop, but also a source of traditional medicinal ingredient, having hypoglycemic, antiviral, antidiabetic , and antitumorigenic functions $[1,2]$. The extracts of the fruit pulp and seed have been reported to have various medicinal properties, including antitumoir and antimutagenic activities. However, in Chinese traditional medicine, the plant is usually used as a hypoglycemic and antidiabetic agent and many components have been identified from $M$. charantia, which possess hypoglycemic properties. One of the active components responsible for this action is charantin. The methods for the separation and purification of charantin from Momordica charantia have been proposed. Generally, several solvents with different polarities should be used to separate it from other contaminants. The yield and/or purity of the charantin are relatively low. Furthermore, such processes in industrial applications inevitably consume a massive amount of organic solvent and the danger of explosion necessitates special equipment leading to increased costs.

Aqueous two-phase systems (ATPS), especially poly (ethyleneglycol) (PEG) /salt systems, have been widely used for the purifying biological materials in biochemistry and biotechnology because of their low cost and wide range of hydrophobicity differences between the two-phase systems $[3,4]$. Employing these phase systems can enhance the partition selectivity of target products, especially for hydrophobic

*Address correspondence to this author at the School of Pharmacy, Shandong University of Traditional Chinese Medicine, Jinan, P.R China; Tel: +86-531-82613129; Fax: +86-86-531-82613129;

E-mail: biobook@163.com products [5]. Numerous reports dealing with macromolecule partition in an aqueous two-phase system have been published, mostly involving proteins or enzymes. Few cases of the partition of small molecules were studied. The present work studies the partition behavior of charantin in a smallscale aqueous two-phase extraction system. Before such a scheme can be developed, it is necessary to determine the distribution of these molecules in an aqueous two-phase system and how to manipulate the system to achieve the desirable partition. Thus, response surface methodology (RSM) had been considered as a useful method to optimize the extraction condition for production of charantin.

Response surface methodology (RSM), which has been extensively applied in optimization of medium composition, conditions of enzymatic hydrolysis, fermentation and food manufacturing processes $[6,7]$, is a collection of statistical techniques for experiment designing, model developing, factors evaluating, and optimum conditions searching. But it has not yet been reported as a means to optimize conditions of charantin from Momordica charantia.

In this paper, we describe the direct extraction of charantin from Momordica charantia using the property that the PEG/salt aqueous two-phase systems can extract hydrophobic proteins. The objective of this study was to investigate and optimize the operating conditions of the charantin extraction in Momordica charantia using RSM.

\section{METHODS AND MATERIALS}

\subsection{Chemicals and Reagents}

PEG 4000 was obtained from Fluka. $\mathrm{K}_{2} \mathrm{HPO}_{4}$ was from Beijing Chemical Reagent Co. and were of analytical grade. The Ginsenoside Rg1 used as standard, was obtained from National Institute for the Control of Pharmaceutical and Biological Products. Xiaoke pills were purchased from Jilin Liuhe Pharmaceutic Factory, China. Xiaoke pill is a kind of Chinese medicine used in the treatment of diabetes. 


\subsection{Plant Material}

Momordica charantia were collected in Jinan, China, in June 2006, and identified by Dr. Z. Feng, Shandong University of Traditional Chinese Medicine.

\subsection{Preparation for Samples}

The fine powders of Momordica charantia for extraction study were prepared by milling dry Momordica charantia with a mechanical grinder and sieving through a 20-mesh metal sieve. Fifty gram of powders was mixed with $1000 \mathrm{ml}$ water. After boiling for 30-40 min, the mixture was subject to filtration with a 100 -mesh metal sieve. The $245 \mathrm{ml}$ filtrate (crude water extract) were collected and used directly for further experiment.

\subsection{Aqueous Two-Phase Extraction}

An aqueous two-phase system was prepared by adding various amounts (indicated in the text) of PEG, $\mathrm{K}_{2} \mathrm{HPO}_{4}$ and ethanol to various amounts of crude water extract. The system was vortexed to form a homogeneous phase. Then it was centrifuged at $3000 \mathrm{~g}$ for $5 \mathrm{~min}$ to facilitate the phase separation. The charantin-containing salt-rich layer was separated and subject to back-extraction three times with $95 \%$ ethanol. The ethanol extracts were collected and kept at $4{ }^{0} \mathrm{C}$ overnight to allow salt to precipitate. After removing the precipitant by centrifugation, the amounts of charantin were analyzed by ultraviolet spectrophotometry.

\subsection{Estimation of Hypoglycemic Activity of Charantin Prepared by Aqueous Two-Phase (CPATP)}

Thirty-six hyperglycemic mice were allocated equally into 3 groups: Alloxan-induced hyperglycemic group, alloxan and Xiaoke Pill-treated group, alloxan and CPATP treated groups. The other 12 normal mice were injected (iv) with the normal saline and used as the control group. From then on, the 4 groups of mice were administered (ig) saline, Xiaoke Pill $(200 \mathrm{mg} / \mathrm{kg} / \mathrm{d})$, CPATP, and saline respectively. On the $20^{\text {th }}$ day, after fasting the mice for $12 \mathrm{~h}$, blood samples were obtained from the tail veins to determine the blood glucose levels [8].

\subsection{Experimental Design and Evaluation}

RSM was used to investigate the influence of various amounts of PEG, $\mathrm{K}_{2} \mathrm{HPO}_{4}$, ethanol and crude water extract (sample loading) on the yield of charantin. A Box-Behnken factorial design with four factors and three levels, including three replicates at the center point, was used for fitting a second-order response surface. Tables $\mathbf{1}$ and $\mathbf{2}$ gave the factors, their values, and the experimental design, respectively. A mathematical model, describing the relationships between the process indices (charantin) and the factors in secondorder equation, was developed as follows:

$\mathrm{Y}=B_{0^{+}}+\sum_{i=1}^{n} B i X i+\sum_{i=j=1}^{n} B i j X i X j$

Where $\mathrm{Y}$ is the predicted response variable; $B_{0}, B_{i}, B_{i j}$ are constant regression coefficients of the model, and $X_{i}, X_{j}$ represent the independent variables in the form of coded values. The accuracy and general ability of the above polynomial
Table 1. Variables and Experimental Design Levels for Response Surface

\begin{tabular}{|c|c|c|c|c|}
\hline \multirow{2}{*}{$\begin{array}{c}\text { Independent } \\
\text { Variables }\end{array}$} & \multirow{2}{*}{$\begin{array}{c}\text { Coded } \\
\text { Symbols }\end{array}$} & \multicolumn{3}{|c|}{ Levels } \\
\hline & & -1 & 0 & 1 \\
\hline $\mathrm{K}_{2} \mathrm{HPO}_{4}(\mathrm{~g})$ & $X_{1}$ & 1.0 & 1.2 & 1.4 \\
\hline PEG (g) & $X_{2}$ & 0.96 & 1.12 & 1.28 \\
\hline Ethanol (ml) & $X_{3}$ & 0 & 0.2 & 4 \\
\hline Sample loading $(\mathrm{ml})$ & $X_{4}$ & 6 & 9 & 12 \\
\hline
\end{tabular}

Table 2. Box-Behnken Design Matrix and the Responses of the Dependent Variables Charantin

\begin{tabular}{|c|c|c|c|c|c|}
\hline \multirow{2}{*}{$\begin{array}{c}\text { Runs } \\
\mathbf{X}_{1}\end{array}$} & \multicolumn{3}{|c|}{ Independent Variables } & \multicolumn{2}{|c|}{ Dependent Variables } \\
\hline & $\mathbf{X}_{2}$ & $\mathbf{X}_{3}$ & $\mathbf{X}_{4}$ & $\mathbf{Y}_{1}$ & (A) \\
\hline 1 & 1.0 & 0.96 & 0.2 & 9 & 0.007 \\
\hline 2 & 1.0 & 1.28 & 0.2 & 9 & 0.005 \\
\hline 3 & 1.4 & 0.96 & 0.2 & 9 & 0.008 \\
\hline 4 & 1.4 & 1.28 & 0.2 & 9 & 0.006 \\
\hline 5 & 1.2 & 1.12 & 0.0 & 6 & 0.004 \\
\hline 6 & 1.2 & 1.12 & 0.0 & 12 & 0.013 \\
\hline 7 & 1.2 & 1.12 & 0.4 & 6 & 0.005 \\
\hline 8 & 1.2 & 1.12 & 0.4 & 12 & 0.011 \\
\hline 9 & 1.0 & 1.12 & 0.2 & 6 & 0.002 \\
\hline 10 & 1.0 & 1.12 & 0.2 & 12 & 0.007 \\
\hline 11 & 1.4 & 1.12 & 0.2 & 6 & 0.004 \\
\hline 12 & 1.4 & 1.12 & 0.2 & 12 & 0.008 \\
\hline 13 & 1.2 & 0.96 & 0.0 & 9 & 0.011 \\
\hline 14 & 1.2 & 0.96 & 0.4 & 9 & 0.010 \\
\hline 15 & 1.2 & 1.28 & 0.0 & 9 & 0.006 \\
\hline 16 & 1.2 & 1.28 & 0.4 & 9 & 0.005 \\
\hline 17 & 1.0 & 1.12 & 0.0 & 9 & 0.004 \\
\hline 18 & 1.0 & 1.12 & 0.4 & 9 & 0.003 \\
\hline 19 & 1.4 & 1.12 & 0.0 & 9 & 0.003 \\
\hline 20 & 1.4 & 1.12 & 0.4 & 9 & 0.004 \\
\hline 21 & 1.2 & 0.96 & 0.2 & 6 & 0.012 \\
\hline 22 & 1.2 & 0.96 & 0.2 & 12 & 0.014 \\
\hline 23 & 1.2 & 1.28 & 0.2 & 6 & 0.005 \\
\hline 24 & 1.2 & 1.28 & 0.2 & 12 & 0.014 \\
\hline 25 & 1.2 & 1.12 & 0.2 & 9 & 0.013 \\
\hline 26 & 1.2 & 1.12 & 0.2 & 9 & 0.013 \\
\hline 27 & 1.2 & 1.12 & 0.2 & 9 & 0.014 \\
\hline
\end{tabular}


model could be evaluated by the coefficient of determination $\mathrm{R}^{2}$.

\subsection{Data Analysis}

Data from the Box-Behnken factorial design shown in Table $\mathbf{2}$ were used for determining the regression coefficients of the second-order multiple regression model. The analysis of regression and variance (ANOVA) was carried out using the RSREG procedure of the SAS statistical package (version 8.1, SAS Institute, Cary, NC, USA). The 3D response surface and contour plot analysis were made by keeping two independent variables at constant level and changing the other two independent variables, and then calculating the response variables using RSREG analysis.

\section{RESULTS}

Table 3 showed the analysis of variance (F-test) for this experiment, and the coefficient of determination $\left(R^{2}\right)$ was shown as $96.52 \%$. This indicated that, the accuracy and general ability of the polynomial model was good, analysis of the response trends using the model was considered to be reasonable.
The regression coefficients, along with the corresponding P-values, for the model of the charantin production, were also presented in Table $\mathbf{3}$. The P-values are used as a tool to check the significance of each coefficient, which also indicate the interaction strength between each independent variable.

Table 3 showed that, the regression coefficients of $X_{2}$, $\mathrm{X}_{4}, \mathrm{X}_{1}{ }^{2}, \mathrm{X}_{3}{ }^{2}$ and $\mathrm{X}_{2} \mathrm{X}_{4}$ were significant at $1 \%$ level, and $\mathrm{X}_{4}{ }^{2}$ was also significant at $5 \%$ level. So the polynomial model for charantin yield Y was regressed by only considering the significant terms and was shown as below:

$\mathrm{Y}=0.01333-0.00175 \mathrm{X}_{2}+0.0029167 \mathrm{X}_{4}+0.00175 \mathrm{X}_{2} \mathrm{X}_{4}$ $0.006167 \mathrm{X}_{1}^{2}-0.003917 \mathrm{X}_{3}{ }^{2}-0.001417 \mathrm{X}_{4}{ }^{2}$

The model (2) indicated that sample loading $\left(\mathrm{X}_{4}\right)$ had a significant effect $(\mathrm{P}<0.001)$ on $\mathrm{Y}$ as it had the largest coefficient followed by PEG (X2). Positive coefficient indicated a linear effect to increase Y. However, negative effects indicated a linear effect to decreases $\mathrm{Y}$. The quadratic terms $\left(\mathrm{X}_{1}\right.$, $\left.\mathrm{X}_{2}, \mathrm{X}_{3}\right)$ had negative effects while interaction term $\left(\mathrm{X}_{2} \mathrm{X}_{4}\right)$ had positive effects on $\mathrm{Y}$.

The 3D response surface based on independent variables PEG $\left(\mathrm{X}_{2}\right)$ and sample loading $\left(\mathrm{X}_{4}\right)$ was shown in Fig. (1),

Table 3. Results of Regression Analysis of a Full Second-Order Polynomial Mode for Optimization of Production of Charantin

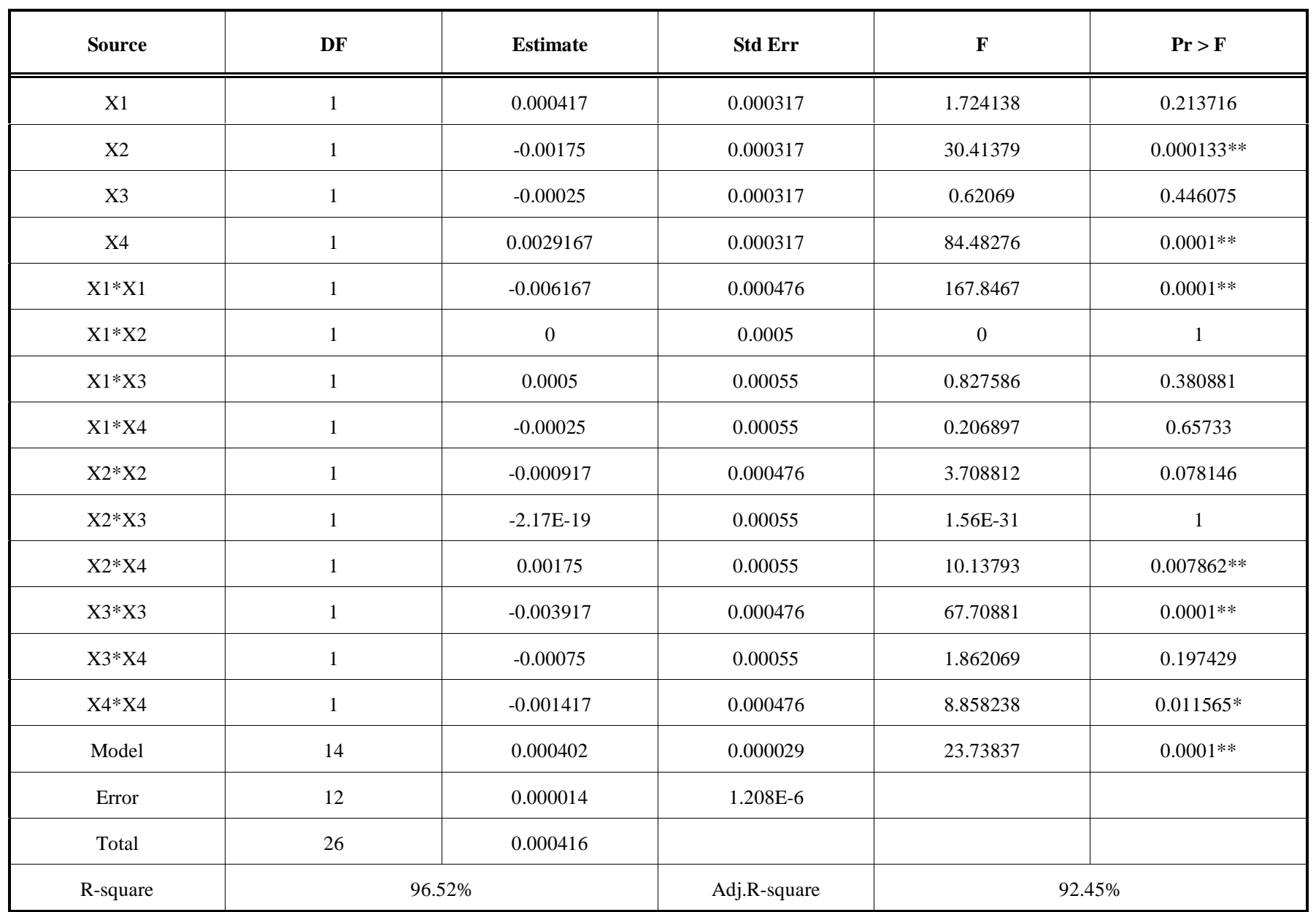

* Significant at $5 \%$ level.

** Significant at $1 \%$ level. 
while the other independent variables, $\mathrm{K}_{2} \mathrm{HPO}_{4}\left(\mathrm{X}_{1}\right)$ and ethanol $\left(\mathrm{X}_{3}\right)$ were kept at a constant level. The interaction relationship between the two independent variables $\left(\mathrm{X}_{2}, \mathrm{X}_{4}\right)$ can be easily understood by examining the contour plots generated by keeping independent variables $\left(\mathrm{X}_{1}, \mathrm{X}_{3}\right)$ as constant (Fig. 2). Canonical analysis revealed a maximum production yield of charantin of 0.15 , could be achieved at the point when $\mathrm{K}_{2} \mathrm{HPO}_{4}$, PEG, ethanol and sample loading were set at $1.2 \mathrm{~g}, 1.12 \mathrm{~g}, 0.2 \mathrm{ml}, 12 \mathrm{ml}$, respectively.

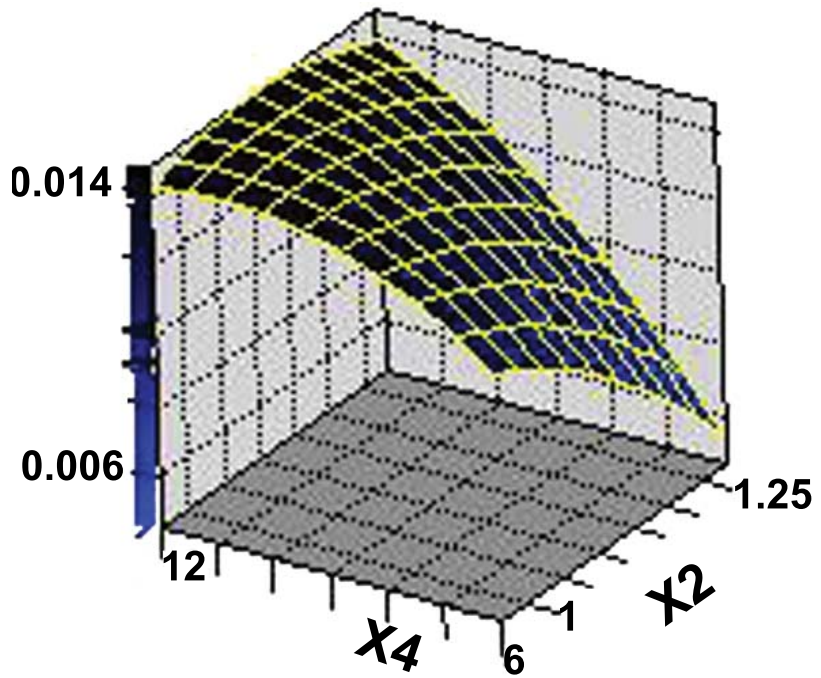

Fig. (1). Surface plot of the combined effects of PEG $\left(X_{2}\right)$ and sample loading $\left(X_{4}\right)$ on the yield of charantin $\left(X_{1}=1.2 \mathrm{~g}, X_{3}=0.2 \mathrm{~g}\right)$.

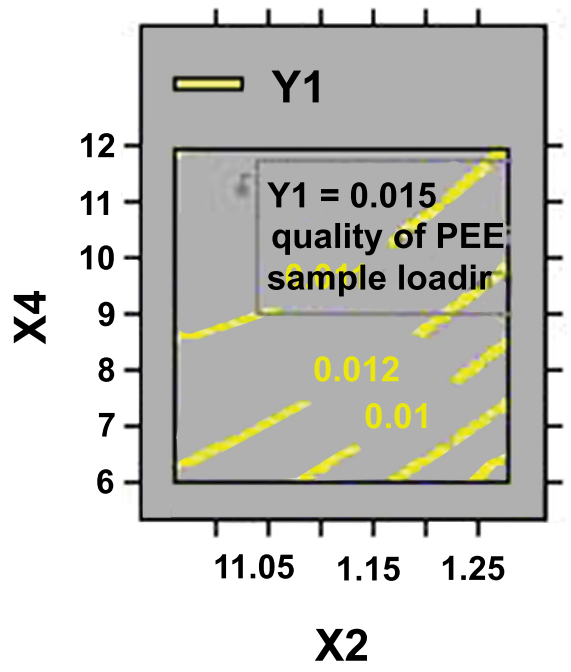

Fig. (2). Contour plot of the combined effects of PEG and sample loading on the yield of charantin, keeping independent variables $\left(\mathrm{X}_{1}, \mathrm{X}_{3}\right)$ as constant $\left(\mathrm{X}_{1}=1.2 \mathrm{~g}, \mathrm{X}_{3}=0.2 \mathrm{~g}\right)$.

The availability of the regression model (2) of the charantin production was tested using the calculated optimal conditions: $\mathrm{K}_{2} \mathrm{HPO}_{4} 1.2 \mathrm{~g}$, PEG $1.12 \mathrm{~g}$, ethanol $0.2 \mathrm{ml}$ and sample loading $12 \mathrm{ml}$ with triplicate experiments. The mean value was 0.0148297 , which agreed with the predicted value 0.015 well.

The results of blood glucose from hyperglycemic mice induced by alloxan are presented in Table 4 . The levels of blood glucose decreased after administration of CPATP and the Xiaoke Pill $(p<0.05)$.
Table 4. Effect of CPATP on Blood Glucose Levels in Alloxan-Hyperglycemic Mice

\begin{tabular}{|c|c|}
\hline Different Groups & Blood Glucose $(\mathbf{m m o l} / \mathbf{L})$ \\
\hline \hline Alloxan- treated & $21.9 \pm 2.9^{\mathrm{a}}$ \\
\hline Alloxan and Xiaoke Pill-treated & $12.8 \pm 3.0^{\mathrm{b}}$ \\
\hline Alloxan and CPATP-treated & $11.0 \pm 6.1^{\mathrm{b}}$ \\
\hline Control group & $6.0 \pm 1.8$ \\
\hline
\end{tabular}

The different letters in the same column indicate a statistical difference $(p<0.05)$.

\section{DISCUSSION}

The quantitative partition of charantin derived from the crude extract of Momordica charantia in an aqueous twophase system has been reported. Statistical experimental designs proved to be useful tools in optimizing charantin extraction in PEG/salt ATPS. RSM model, which could overcome the limitations of classic empirical methods, was proposed to study the combined effects of phase-forming components. The phase-forming components: PEG and sample loading, strongly affected yield of charantin. The optimal aqueous two-phase system for charantin extraction was $\mathrm{K}_{2} \mathrm{HPO}_{4} 1.2 \mathrm{~g}$, PEG $1.12 \mathrm{~g}$, ethanol $0.2 \mathrm{ml}$ and sample loading $12 \mathrm{ml}$.

In China, many farmers plant Momordica charantia as vegetable. If it is used to separate charantin, the farmers will benefit from it. Aqueous two-phase systems (ATPS) were used for the purifying saponin because of their low cost. ATPS can reduce amount of organic solvent and the danger of explosion necessitates special equipment leading to increased costs.

\section{ACKNOWLEDGMENT}

This project is supported by Science and Technology Program of Shandong Education Department of China (J08LH62). This work was also supported by Shandong University of Traditional Chinese Medicine in 2008(200819).

\section{REFERENCES}

[1] Ho WKK, Liu SC, Shaw PC, et al. Cloning of the cDNA of alphamomorcharin: a ribosome inactivating protein. Biochem Biophys Acta 1991; 1088: 311-4.

[2] Raza H, Ahmed I, Lakhani MS, et al. Effect of bitter melon (Momordica charantia) fruit juice on the hepatic cytochrome P450dependent monooxygenases and glutathione S-transferases in streptozotocin-induced diabetic rats. Biochem Pharmacol 1996; 52: $1639-42$.

[3] Walter H, Brooks DE, Fisher D. Partitioning in aqueous two-phase systems: theory, methods, uses, and applications to biotechnology. Academic Press: Orlando, FL 1985.

[4] Eiteman MA, Gainer JL. Peptide hydrophobicity and partitioning in poly(ethylene glycol)/magnesium sulfate aqueous two-phase systems. Biotechnol Prog 1990; 6: 479-84.

[5] Li C, Ouyang F, Bai J. Extractive cultivation of Lactococcus lactis using a poly(ethylene glycol)/ $\mathrm{MgSO}_{4}-7 \mathrm{H}_{2} \mathrm{O}$ aqueous two-phase systims to produce nisin. Biotechnol Lett 2000; 22: 843-7.

[6] Shi Y, Weimer PJ. Response surface analysis of the effects of $\mathrm{pH}$ and dilution rate on Ruminococcus flavefaciens FD-1in cellulosefed continuous culture. Appl Environ Microbiol 1992; 58: 2583-91. 
[7] Oh S, Rheem S, Sim J, Kim S, Baek Y. Optimizing conditions for the growth of Lactobacillus casei YIT 9018 in tryptone-glucose medium by using response surface methodology. Appl Environ Microbiol 1995; 61: 3809-14.
[8] Han C, Hui Q, Wang Y. Hypoglycaemic activity of saponin fraction extracted from Momordica charantia in PEG/salt aqueous twophase systems. Nat Prod Res 2008; 22(13): 1112-9.

(C) Han and Wang; Licensee Bentham Open.

This is an open access article licensed under the terms of the Creative Commons Attribution Non-Commercial License (http://creativecommons.org/licenses/ by-nc/3.0/) which permits unrestricted, non-commercial use, distribution and reproduction in any medium, provided the work is properly cited. 